\title{
PULSELESS DISEASE A REPORT ON FIVE CASES
}

\author{
BY \\ R. A. CALDWELL AND E. W. SKIPPER \\ From the University Department of Pathology and the Royal Infirmary at Sheffield
}

Received March 28, 1960

Pulseless disease or Takayashu's disease is a rare condition characterized by the completc, or almost complete, absence of the arterial pulsation in the upper extremities, and usually in the head and neck, due to an obliterative process in the great branches of the aortic arch. Although wellknown by Japanese writers, it has received little attention in this country. The earliest recorded case was that of a woman aged 22 described by Savory (1856). A further example was reported by Broadbent (1875) in a man aged 50 years. Other instances of the disease have been reported from time to time, some of them being associated with syphilitic aortic aneurysm. Skipper and Flint (1952) collected 18 cases of pulseless disease including two of their own, and Ross and McKusick (1953) reviewed very fully over 100 cases of what they termed "aortic arch syndromes" with various combinations of stenosis and obliteration of branches of the aortic arch due to a variety of causes. In the early part of this century, Japanese authors had drawn attention to the relative frequency of Takayashu's disease in their country and Caccamise and Whitman (1952) collected 58 cases from Japanese sources. Probably at least one hundred and twenty have so far been described. Since 1948 five cases of pulseless disease have bəen observed in the Sheffield Royal Infirmary: two proved fatal and the post-mortem and histological findings are given here. The clinical features of Cases 1 and 2 have in large part been previously described (Skipper and Flint, 1952).

Case 1. A man, aged 42, of poor physique, complained in June 1948 of attacks of transient blurring of vision and faintness on standing. He once lost consciousness momentarily when tilted backwards in the barber's chair. He had no Jewish ancestry and there was no family history of hypertension.

Pulsation was absent at both wrists and only barely felt in the left brachial, left axillary, and left common carotid arteries. It was absent from these vessels on the right side and from both subclavian arteries. The blood pressure could not be registered in either arm. Normal pulsation was felt over the abdominal aorta and in the lower limbs. The blood pressure in the right leg averaged $200 / 130 \mathrm{~mm}$. $\mathrm{Hg}$ and in the left leg 240/140. Clinical examination of the heart and the electrocardiogram were normal. Ophthalmoscopic examination revealed no abnormality of the lenses, but there was a visible circulation in the main branches of the retinal arteries, the blood flowing slowly and evenly without pulsation. This phenomenon was seen particularly when the patient felt faint but was seldom seen in two vessels simultaneously. X-ray examination of the heart and lungs and an angiocardiogram were normal but none of the great vessels arising from the aortic arch could be traced very far. Biopsies of the left brachial artery at three levels showed no abnormality. Comprehensive blood and urine examinations revealed no significant abnormality and the Wassermann reaction was negative. By May 1951 the patient was blind in the right eye with complete cataract and the left eye showed incipient lens opacities. Light pressure on the ball of the left eye caused collapse and blanching of all the retinal vessels. Apart from the visual defect he remained well and moderately active.*

* Addendum. Case 1. This patient died in October 1959, after this paper was first submitted, and at autopsy the arterial changes were similar to those in Case 2. The cause of death was carcinoma of the lung. 
Case 2. A married woman, aged 37, was admitted into Sheffield Royal Infirmary during February 1949 , complaining of failing eyesight. When training as a nurse at the age of 19 she had noted that her own pulse was normal. During successive pregnancies in 1936 and 1937 she suffered from frequent transient faintness without loss of consciousness and such attacks continued after the second pregnancy. Recurrent abdominal pain led to hysterectomy in 1944, this being immediately followed by severe headaches and thirteen days later by right hemiplegia. Simultaneously she became practically blind, but vision returned in a week and the hemiplegia slowly recovered, although the headaches continued. In 1947 the vision in her right eye began to fail for increasingly longer periods and in November 1948 she lost the vision in both eyes for several hours. Thereafter her eyesight deteriorated steadily with frequent periods of blindness, and the fainting attacks became much more severe, causing her to fall many times each day. Her doctor was unable to feel her pulse or to record her blood pressure. She was a light smoker and had no known Jewish ancestry.

Her general condition and colour were good and her intelligence average; weight 7 st. $12 \mathrm{lb}$. (49.9 kg.). Pulsation could not be felt in the arteries in the neck or arms and the blood pressure could not be measured in the arms. Pulsation in the abdominal aorta and femoral arteries was strong and the blood pressure in the legs was $150 / 90 \mathrm{~mm}$. Hg. Many collateral pulsating vessels could be felt over the back of the chest, a bruit being heard over several. A loud continuous murmur, most pronounced in systole, was present just above the inner end of the left clavicle. Peripheral skin circulation was normal. The heart, lungs, and abdomen were normal clinically.

The patient's vision was poor, and both fundi showed many exudates, hæmorrhages, and considerable venous engorgement, with segmentation of the circulating blood in the veins. At the base of each iris, in the position of the contraction groove, was a newly formed circular vessel. The pupils were dilated, and did not react to light or accommodation. Examination of the nervous system was normal. Cardiograms and X-rays of the heart and lungs were normal except for the presence of small bilateral cervical ribs. The cerebrospinal fluid was normal and the Wassermann reaction was negative in it and in the blood. The urine contained no abnormality and renal efficiency tests and an intravenous pyelogram were normal. A

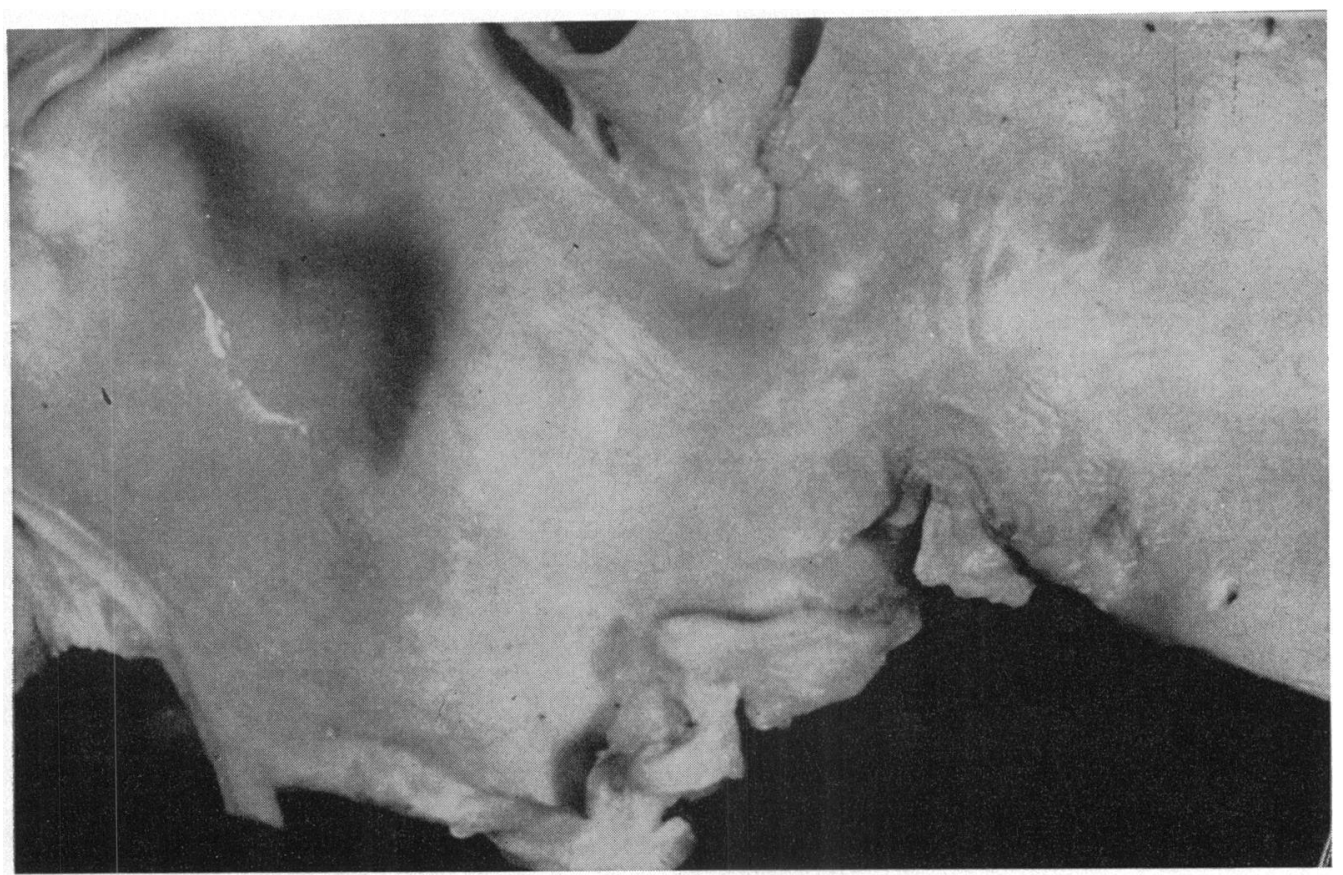

FIG. 1.-Case 2. The site of the aortic coarctation. Note the aneurysmal dilatation of the ascending part of the arch. 
blood count showed a mild hypochromic anæmia, the hæmoglobin being 68 per cent. The corrected E.S.R. (Wintrobe) was $30 \mathrm{~mm}$. in 1 hour. An angiogram carried out via the left common carotid showed good filling of the cerebral vessels. Portions of the right radial and left temporal artery were excited: these vessels appeared to be smaller than the average, but their lumina were patent and no pathological changes were found in their walls.

By September 1949 this patient was blind, bilateral cataracts having formed with atrophy of each iris and ciliary body. The peripheral iritic vessels were now replaced by a pigmented fibrous ring around the base of the iris in each eye. There was degenerative keratitis in the left eye, with superficial vascularization. The headaches continued to be severe, but the syncopal attacks decreased in frequency. A year later intermittent claudication began to make walking difficult. Arterial pulsation below the thighs became difficult to feel and it was not possible accurately to record the blood pressure in the legs. Other symptoms were epigastric and præcordial pain, unrelated to exertion. The cardiogram remained normal. A barium meal in 1954 showed no evidence of ulcer. The hæmoglobin fell to 50 per cent but the anæmia responded to iron therapy. In June 1956 she developed a urinary infection which was quickly fatal.

Necropsy Findings: Cardiovascular System. The heart (360 g.) showed slight hypertrophy of the left ventricle $(1.4 \mathrm{~cm}$. thickness) but it was otherwise normal. There was a small soft atheromatous area on the anterior cusp of the mitral valve but the coronary arteries were healthy. There was moderate dilatation of the ascending aorta, the circumference being $6.5 \mathrm{~cm}$. at a point $3.5 \mathrm{~cm}$. above the aortic valve (Fig. 1). There was considerable intimal scarring and contraction at the sites of origins of the great vessels, and the innominate and left common carotid arose from a common root. Immediately distal to the vessels there was an area of coarctation $1.5 \mathrm{~cm}$. long, where the circumference of the aorta was $2.5 \mathrm{~cm}$. Distal to this the circumference was normal $(5 \mathrm{~cm}$.). Very little atheroma was present in the thoracic portion, but the intima showed fine wrinkling in addition to the scarring round the branches; in the abdominal aorta there was

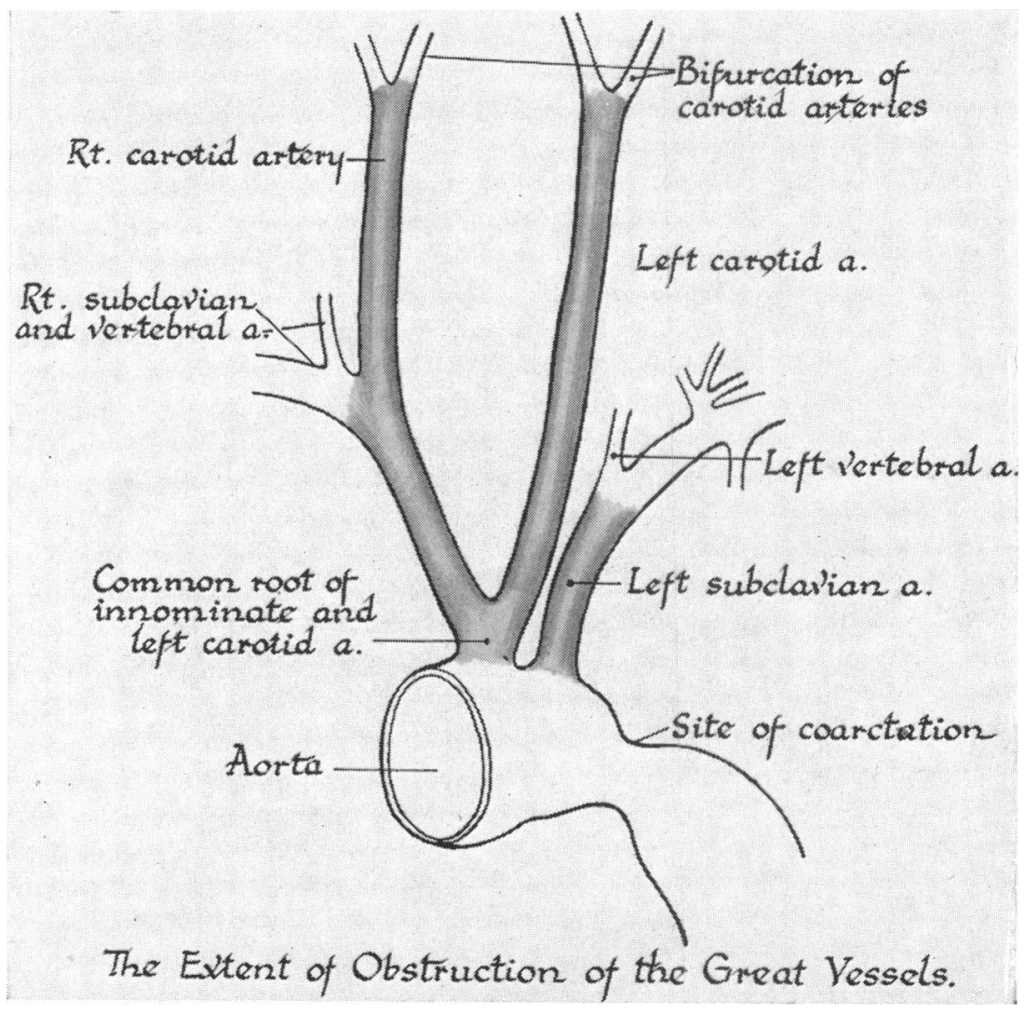

Fig. 2.-Case 2. Drawing showing the extent of the obliterative process. 


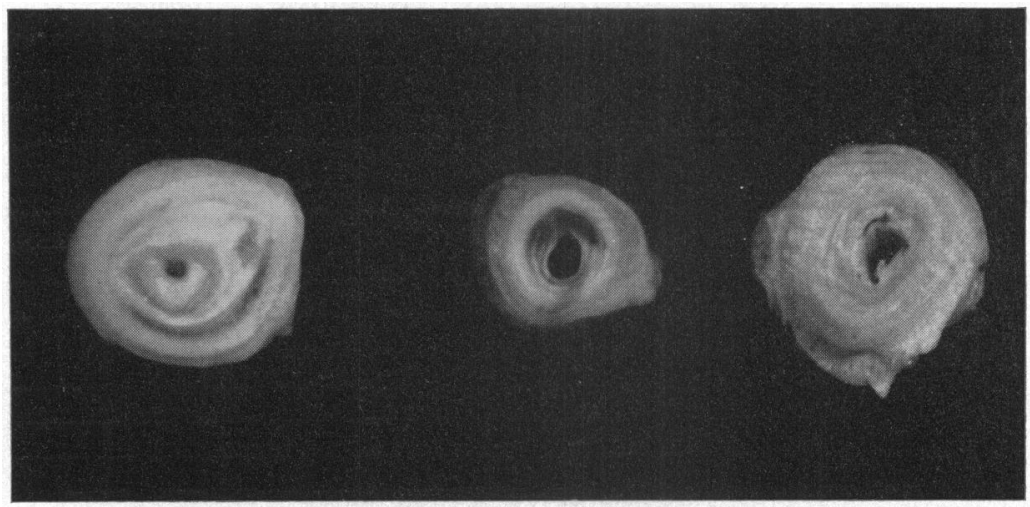

FIG. 3.-Case 2. Cross-sections of the great vessels immediately distal to their origins. The innominate orifice is on the left $(\times 2)$.

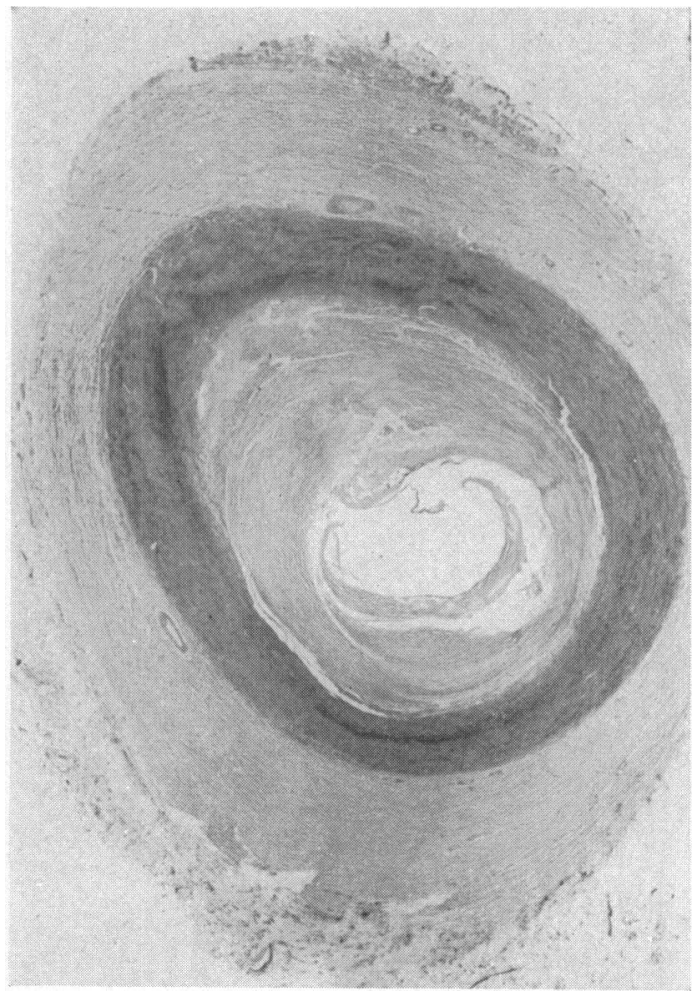

Fig. 4.-Case 2. A section of the left common carotid artery immediately distal to the origin, showing intimal and adventitial thickening. Hæmatoxylin and eosin $(\times 11)$.

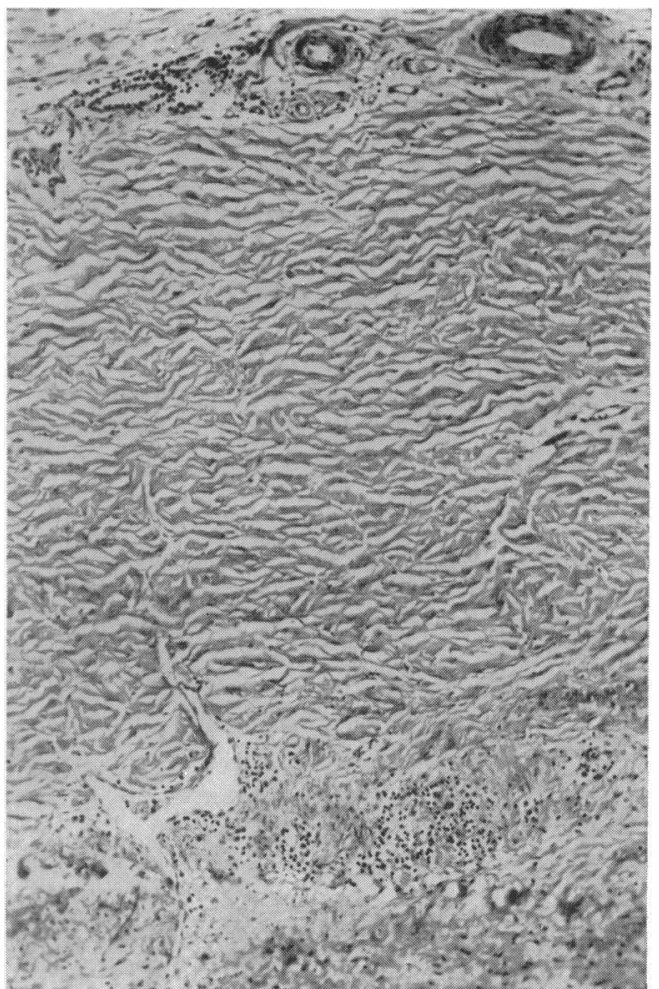

FIG. 5.-Case 2. A section showing detail of the adventitial thickening of the previous figure. There is focal lymphocytic infiltration at the periphery and close to the media. Hæmatoxylin and eosin $(\times 75)$. 
much atheroma with calcification and patchy ulceration beginning at the level of the diaphragm and extending to the bifurcation. White firm concentric intimal thickening at or close to the orifices of the innominate and the left common carotid arteries almost occluded these vessels. The orifice of the left subclavian admitted a $2 \mathrm{~mm}$. probe which could be passed with difficulty through the stenosed proximal $4 \mathrm{~cm}$. of the vessel which thereafter became progressively larger and seemed normal at the site of origin of the left vertebral artery (Fig. 2 and 3).

Alimentary System. The stomach showed two small chronic ulcers on the anterior and posterior walls of the pylorus respectively. Genito-urinary System. The left kidney (wt. $100 \mathrm{~g}$.) was hypoplastic and there were two small cortical abscesses in its upper pole. The right kidney (wt. $300 \mathrm{~g}$.) was moderately enlarged, its cut surface showing a number of scattered abscesses. Central Nervous System. The surface of the brain showed a sunken area in the left fronto-parietal region, the cut surface revealing this as an area of brownish softening. Elsewhere the brain appeared normal and the vessels of the circle of Willis were healthy.

Histological Findings: Aorta. In the ascending portion of the arch there was moderate patchy intimal thickening consisting of fibrinoid and fibrous tissue. In the transverse and descending portions, this thickening was uniform and of moderate depth and in a few places where the structure was loose and reticular, an occasional imprisoned hæmosiderin-laden macrophage was seen. No section showed any stainable muscle throughout the media of the thoracic aorta, but the elastic tissue appeared normal in amount and form. The adventitia was normal apart from a small area of thickening close to the origins of the great vessels where there were also a few small areas of lymphocytic infiltration.

Great Vessels. At their sites of origin, the most striking change was the great increase in depth of the adventitia (Fig. 4) which was composed of concentrically arranged laminæ of acellular collagen. There were many focal infiltrations of plasma cells and lymphocytes in relation to small blood-vessels, principally at the periphery of the adventitia, and at the junction of adventitia and media (Fig. 5). These histological changes were most severe proximally, and gradually diminished in extent peripherally. No giant-cells were seen. The elastic tissue consisted of tightly-waved bands of greater than normal density and thickness and were interrupted here and there by small areas of fibrosis (Fig. 6). The media of the affected portions of the arteries were of normal thickness, but showed a complete absence of stainable muscle fibres and no cellular infiltration (Fig. 7 and 8). The narrowed lumina of the vessels had resulted from an intimal thickening consisting mainly of hyaline collagen, and in some areas the lumen appeared to owe its existence to a recanalization of an occlusion. Close to the media, the fibrous texture was looser and showed numerous small capillary bloodvessels and slight patchy lymphocyte and plasma cell infiltration. Here and there a small imperfectly formed muscular artery was seen. No lipoid appeared in specially stained sections.

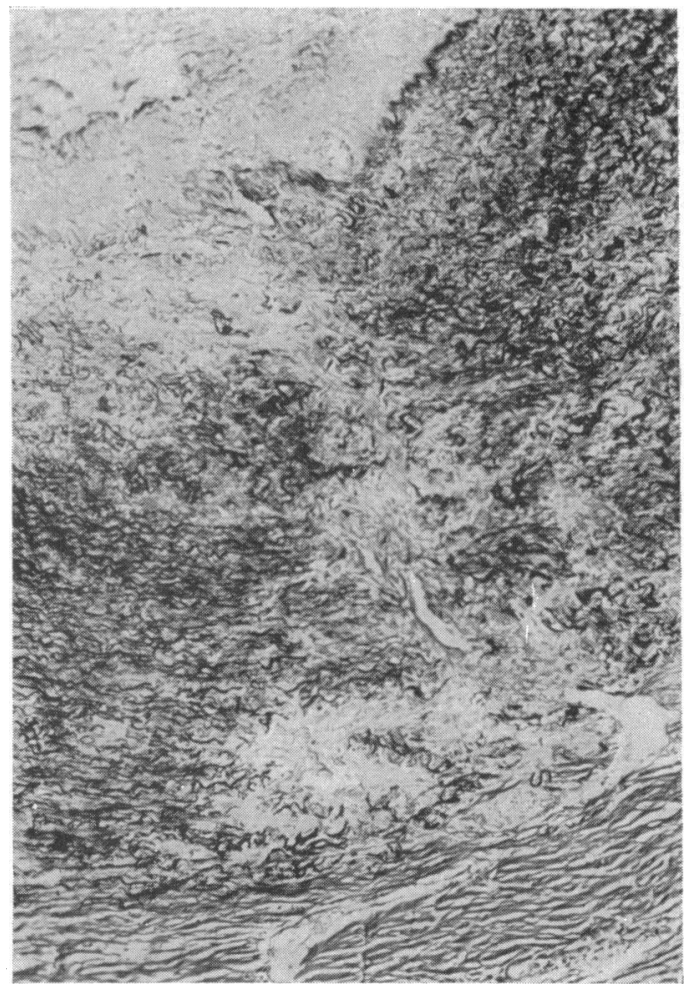

Fig. 6.-Case 2. A section of the left common carotid artery orifice, showing the dense elastic fibres and an area of medial fibrosis. Van Gieson and Verhoeff $(\times 75)$. 


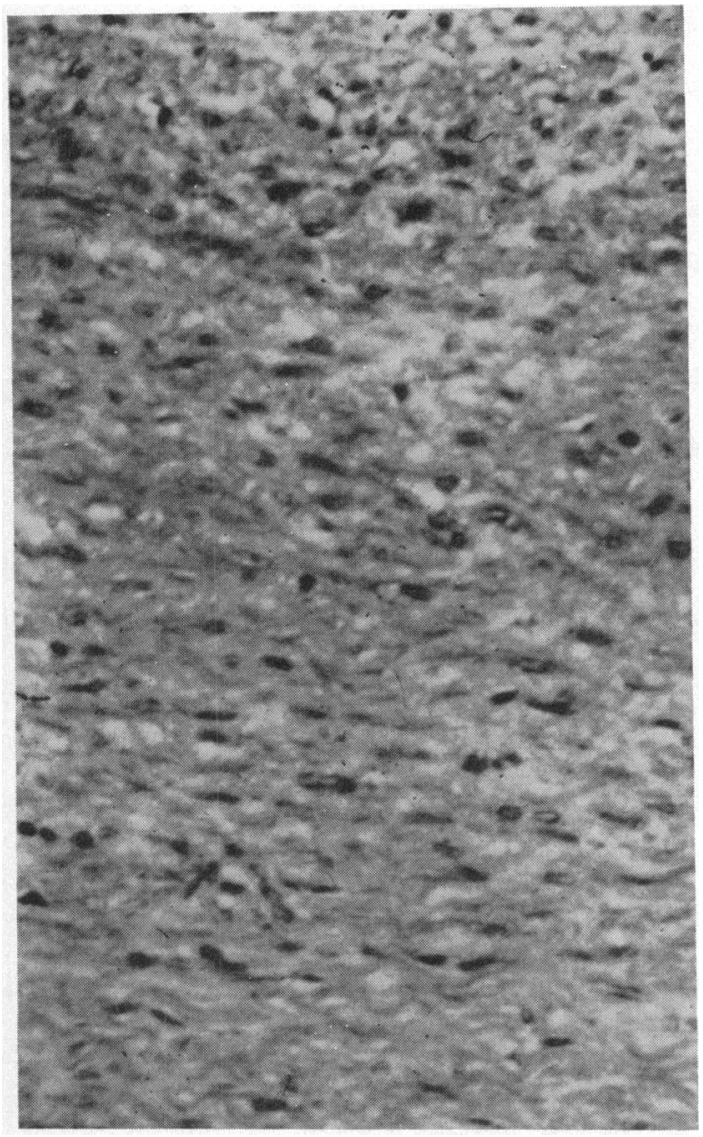

FIG. 7.-Case 2. A section of the media of the innominate artery, showing absence of muscle fibres. Masson's trichrome stain.

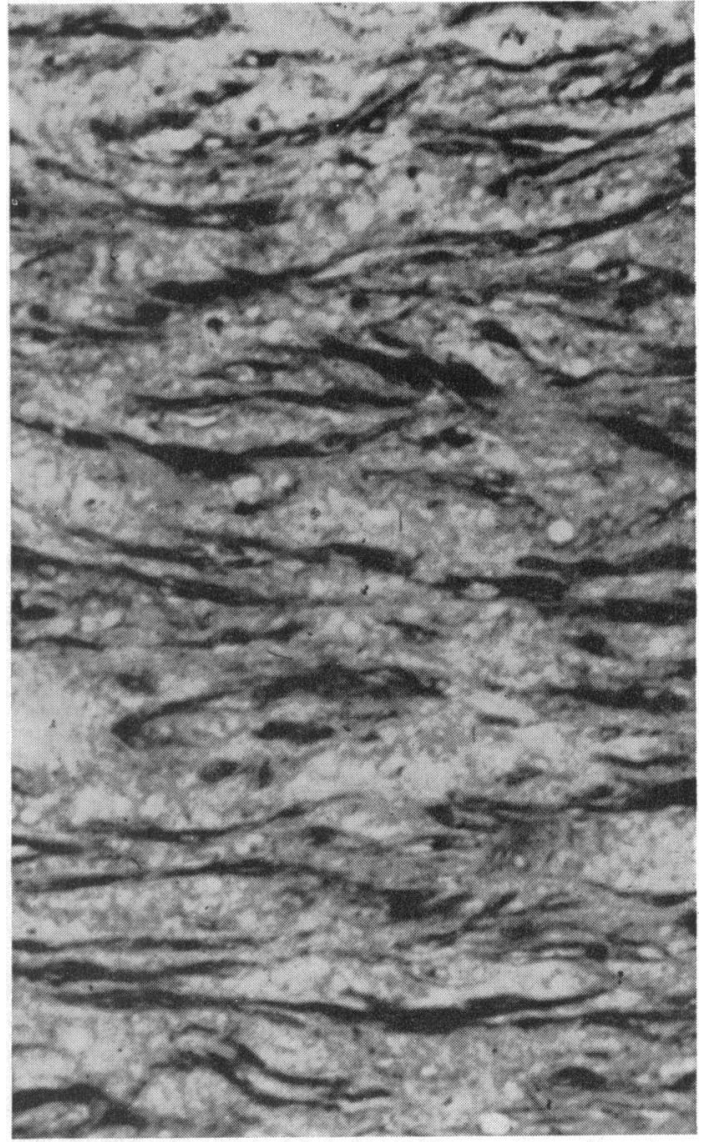

FIG. 8.-Case 2. A section of the media of the innominate artery from a control patient of the same age and sex, showing numerous deeply stained muscle fibres. Masson's trichrome stain $(\times 700)$.

Case 3. A miner, aged 46 , had worked in the pit since the age of 14 years. He was a light smoker, had no known Jewish ancestry, and had had no serious illnesses. He was admitted to hospital in August 1956 with phlebitis of the legs and pulmonary embolism. Histological examination of an excised segment of femoral vein showed only organizing thrombosis. A few months later he developed intermittent claudication in the right leg and no pulsation could be felt below either femoral artery. The radial pulses were palpable and the brachial arterial pressure was 130/90. During the summer of 1957 he complained of "bright flashes" in front of his eyes and experienced occasional transient diplopia. Intermittent claudication was now present in both legs and he suffered from cramp-like pains in the arms when digging. In October 1957 he was again in hospital with severe retro-sternal pain of two days duration associated with transient right hemiplegia. The blood pressure was unobtainable in the right arm but was 120/90 in the left. Despite the absence of cardiographic abnormality he was treated for coronary thrombosis.

When admitted in January 1958 for further investigation, no arterial pulsation could be felt except in the femoral arteries where it was feeble. The blood pressure was unrecordable in all limbs. A systolic bruit could be heard above the right clavicle but no anastomotic circulation could be felt. The arms were pale and no hyperæmia could be induced in them in the dependent position. The legs showed evidence of arterial insufficiency with Lewis' test. No trophic changes were evident in any limb. A further cardiogram was unchanged, and no rib notching could be observed in chest X-rays. Ophthalmoscopy revealed nothing abnormal, the visual fields were full, and visual acuity was L.6/9, R.6/6. The only objective abnormality in 
the nervous system was an extensor plantar response on the right side. Blood examination showed 120 per cent hæmoglobin and a slight leucocytosis (12,000 per cu. mm.). The platelet count was 300,000 per cu. $\mathrm{mm}$. (Lempert) and the bleeding and coagulation times were normal. The corrected sedimentation rate (Wintrobe) was $18 \mathrm{~mm}$. in 1 hour. No L.E. cells were seen in the peripheral blood. The blood urea was $26 \mathrm{mg}$. per $100 \mathrm{ml}$.

The right side of the neck was explored under general anæsthesia. The common carotid and external carotid arteries appeared somewhat smaller than normal and were yellowish in colour. No pulsation could be felt in them and only a small quantity of blood was obtainable on puncture of the former vessel. The innominate artery, which was followed downwards digitally almost to the aorta, was also pulseless. No pulsation could be felt in the external carotid, which was later found to be normal on histological examination. Two days later the patient developed a left hemiplegia which was quickly fatal.

Necropsy Findings: Cardiovascular System. The heart (470 g.) was slightly enlarged due to hypertrophy and dilatation of the left ventricle, the wall of which was $1.7 \mathrm{~cm}$. in thickness. The other chambers, the valves, and muscle were normal. The coronary arteries showed patchy atheroma but no occlusion. The aorta was of normal calibre throughout; the ascending thoracic portion showed an ovoid atheromatous plaque, measuring approximately $2 \times 1 \mathrm{~cm}$., situated just distal to the orifice of the right coronary artery. Antemortem red thrombus was firmly attached to this plaque and from it ribbon-like filamentous extensions, lying free in the aortic lumen, passed proximally through the aortic valve and, distally, to join with a

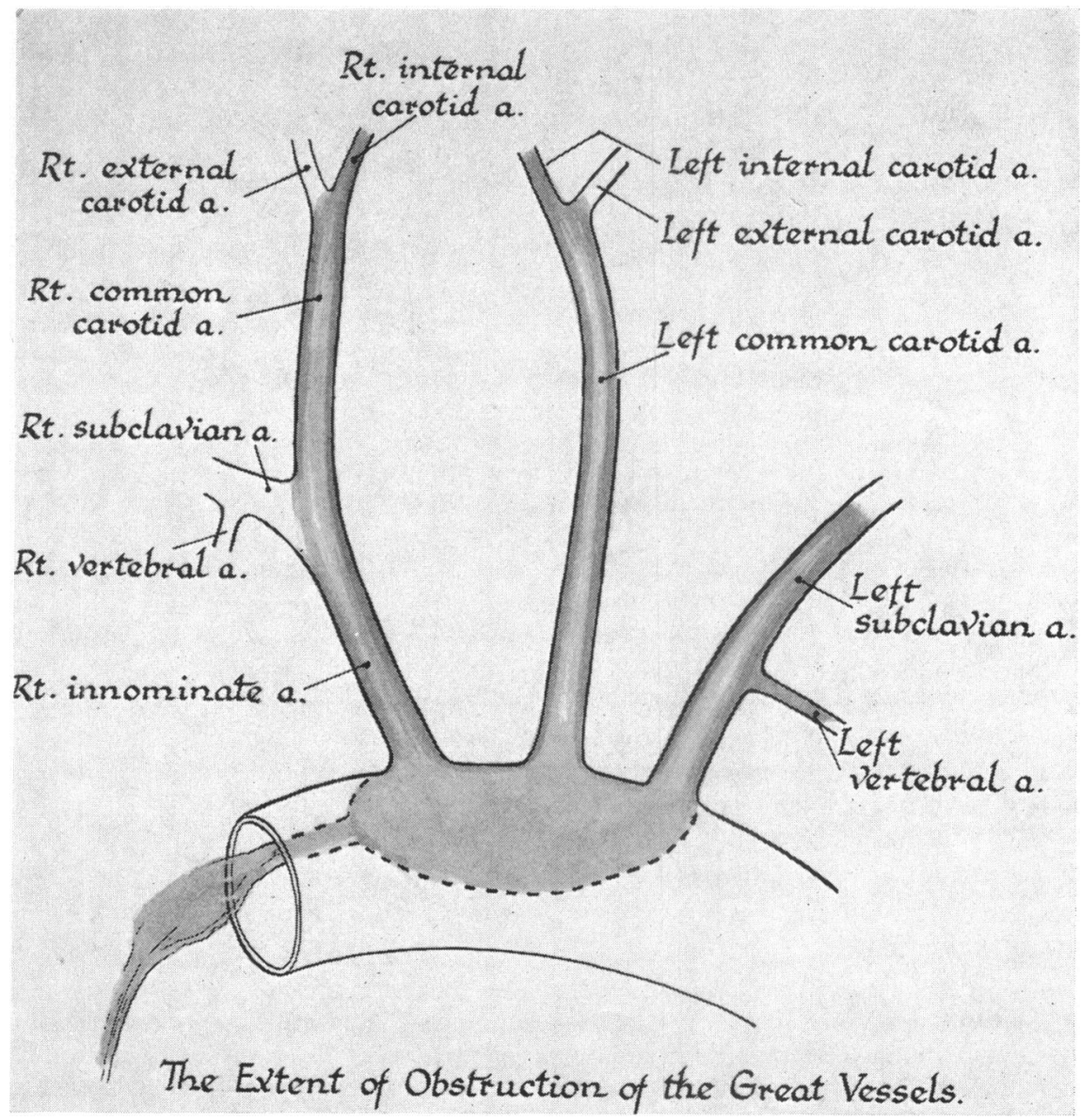

Fig. 9.-Case 3. Drawing showing the extent of the thrombosis. 
cylindrical mass of firm red thrombus, which lay closely applied to and occluded the origins of the great vessels into which it sent propagations (Fig. 9 and 10). Apart from a number of small atheromatous button-like lesions at the orifices of the vertebral arteries, the thoracic aorta was elsewhere normal. Distal to the orifices of the coliac axis and renal arteries, there were several ulcerated atheromatous plaques to which red thrombi were attached. Firm red thrombus completely occluded the innominate, the left subclavian, and the origin of the left common carotid artery, and extended as shown in Fig. 9. The cut surfaces of these vessels showed patchy yellowish atheroma in the walls.

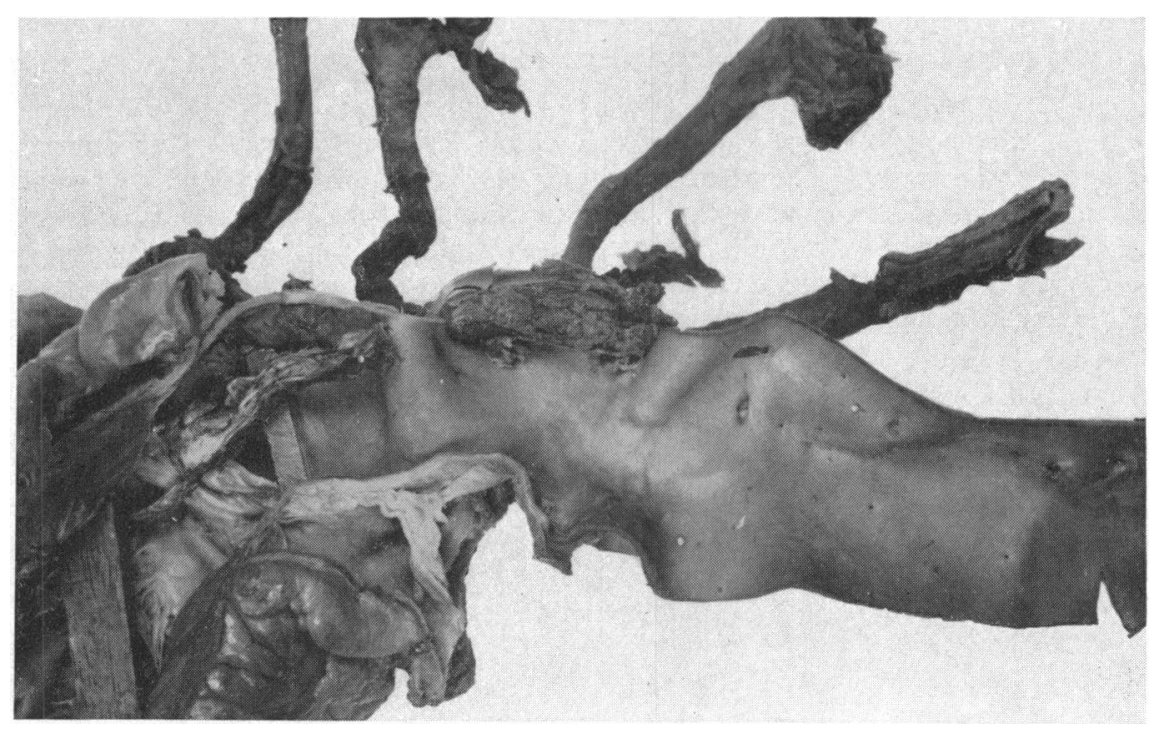

FIG. 10.-Case 3. The heart, thoracic aorta, and great vessels, showing the thrombotic plug occluding the great vessel orifices $(\times 3 / 4)$.

On removal of the brain, firm red thrombus protruded from the severed end of the right middle cerebral artery and there was complete thrombosis of this vessel and its branches. There was slight patchy atheroma of the basilar artery, and the right vertebral artery was considerably larger than the left. The remainder of the circle of Willis appeared normal. The peripheral arteries of the arms and legs also showed areas of thrombotic obstruction. These were situated in the right brachial artery and in the right femoral and popliteal arteries where a segment of pale firm thrombus occluded the femoral artery from the origin of the profunda femoris branch and extended well into the popliteal artery. The superficial and deep veins of the legs showed no apparent abnormality, with the exception of the left popliteal vein which was occluded by pale firm thrombus.

Genito-urinary System. The kidneys (340 g. together) showed areas of old and recent infarction, over which there were fibrous capsular thickenings and adhesions. The ureters, bladder, and prostate were normal.

Central Nervous System. The brain showed a large area of injection and softening in the right hemisphere involving the corpus striatum and corpus callosum. There was evidence of pressure coning around the base of the cerebellum.

Histological Findings: Aorta and Great Vessels. There were numerous typical atheromatous intimal plaques (Fig. 11) and many showed thrombus deposition and integration. Frozen sections from these areas confirmed the presence of abundant sudanophilic material. The muscle fibres and elastic tissue in areas remote from atheromatous plaques appeared normal. Fibrous adventitial thickening was present only in the left subclavian artery, but small adventitial perivascular collections of lymphocytes and plasma cells were seen also in sections of all the vessels where atheroma and thrombosis co-existed. 


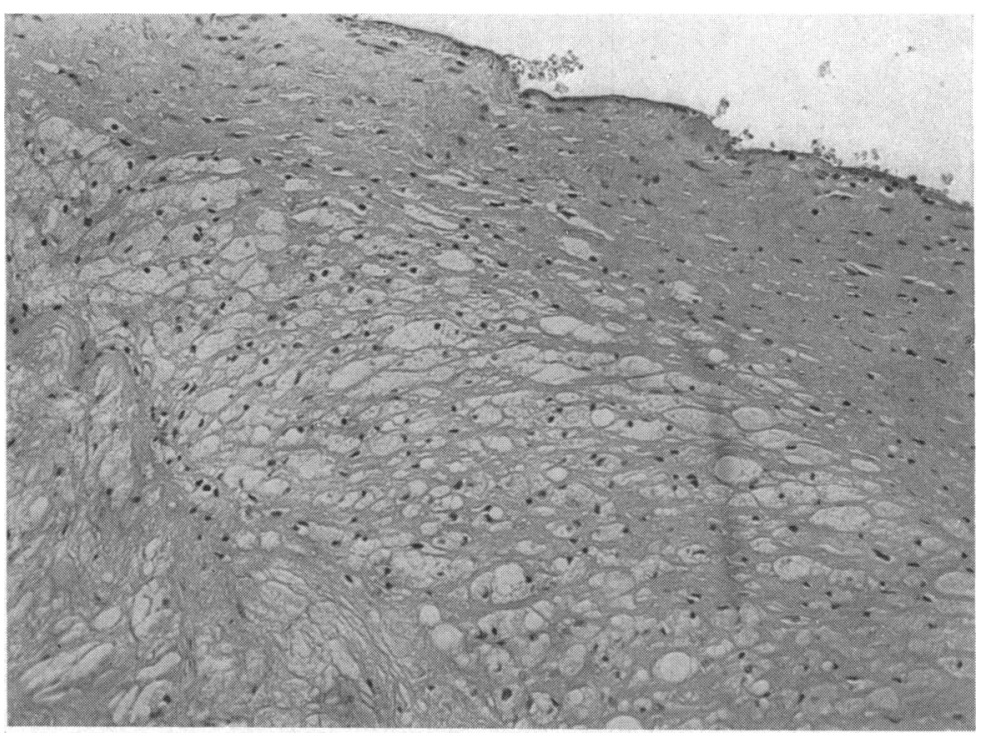

FIG. 11.-Case 3. A section of the distal portion of the innominate artery, showing extensive intimal atheroma. Hæmatoxylin and eosin $(\times 65)$.

Right Middle Cerebral Artery. Lying free in the lumen there was partially organized laminated thrombus. The intima, media, and adventitia showed no intrinsic lesion and the thrombus might well have been of embolic origin.

Peripheral and Visceral Arteries. Atheromatous lesions were widespread and advanced, particularly in the renal interlobular arteries and also in the coronary arteries although there was no evidence of myocardial fibrosis.

Left Popliteal Vein. There was complete occlusion of the lumen by fibrous thrombus in an advanced stage of organization but the media and adventitia showed no inflammatory change or fibrosis.

Case 4. A married woman, aged 28, was admitted to hospital with anxiety symptoms in March 1958. During the latter part of her fifth pregnancy, a year previously, she had begun to experience severe headaches, partial black-outs, weeping fits, and generalized paræsthesiæ, but had never lost consciousness. Five months before admission the brachial arterial pressure had been 100/60.

On examination no arterial pulsation was discoverable in the arms and it was not possible to record the blood pressure in them. Pulsation was present over the upper portions of both carotid arteries and above the right clavicle, where a loud systolic bruit was audible, but no other pulses were felt in the upper part of the body or on the head. Arterial pulsation was normal in the lower limbs and the blood pressure in each was $280 / 180$. The fundi were normal and visual acuity unimpaired. There were no other significant clinical or radiological features, and comprehensive blood, urine, and serological investigations showed no abnormality. It was thought that the symptoms were referable to an anxiety state and not to pulseless disease.

Case 5. A man, aged 69, became depressed after his wife's death in 1949 and attempted suicide in 1954. He was treated by electro-convulsive therapy and eventually by pre-frontal leucotomy. In April 1958 it was noted that his radial pulses were absent. At examination in the following months the brachial arterial pressure could not be measured, arterial pulsation being absent in both arms and axillæ. A systolic murmur was heard above the right clavicle. The blood pressure in the legs was 220/145. The E.S.R. was $30 \mathrm{~mm}$. in $1 \mathrm{hr}$. A chest X-ray was normal and comprehensive laboratory tests of the blood and urine and serum showed no significant abnormality. As in Case 4, it was thought that the vascular abnormalities were causing no symptoms. 


\section{DiscusSION}

Etiology. In pulseless disease, whatever the underlying pathology, an occlusive process occurs in the great branches of the aortic arch, commencing at, or just above, the orifices of these vessels and extending along their walls for a variable distance. Usually the occlusion occurs symmetrically and is slowly progressive, but sudden complete blockage of an artery may occur from thrombosis. The aetiology may be syphilitic aortitis, non-specific arteritis, atheroma, or congenital anomalies of the aortic arch branches.

Syphilitic Aortitis. Ross and McKusick (1953) considered this the commonest cause while Skipper and Flint (1952) found evidence of it in 9 of the 18 cases collected by them. The orifices of the aortic arch branches are involved in the granulomatous process which has been also demonstrated in the proximal portions of the vessel walls. In several instances glove-like projections of ante-mortem clot within an aneurysm have been found extending into and occluding the vessels. Such a case was described by Shikhare (1921).

Non-specific Arteritis. Cases 1 and 2 and probably Case 4 belong to this group. Japanese authors have stressed the preponderance of young women in their cases; of the 58 collected by Caccamise and Whitman (1952) the sex was mentioned in 44 and of these 39 were women with an average age of 23 years: syphilis was not mentioned as a possible cause but syphilitic aortitis would be rare in women of this age. The pathological details in this series are too scanty to be of value. Chronic granulomatous changes, similar to those found by us were reported in a poorly documented paper by Shimizu and Sano (1951) who had observed 8 cases since 1937 . Four examples in women were individually described by Beneke (1925), Harbitz (1926), Frövig and Löken (1951) and by Barker and Edwards (1955). In all, the extent of the arterial obstruction and the histological features closely resembled those of Cases 1 and 2.

There is insufficient evidence to allow the exact pathology of this form of pulseless disease to be defined; its close histological similarity to other types of arteritis, notably to temporal arteritis or "giant-cell arteritis" is evident. We did not observe giant cells in our cases but they were described by Shimizu and Sano (1951) and by Harbitz (1926). Certain histological similarities to polyarteritis nodosa and to Buerger's disease may also be noted. In none of these forms of arteritis, however, does massive, symmetrical arterial occlusion occur, and their clinical features are quite different.

Atheroma. That atheroma alone may, rarely, be the cause of pulseless disease was suggested by Marinesco and Kreindler (1936) and by Sen Gupta and Ghosh (1957), both of whom found severe atheroma of the aortic arch and of the stenosed arteries, the latter containing organizing thrombi. Atheroma may also play a part in producing the obstruction when it complicates syphilitic aortitis as stressed by Cohen and Davie (1933). In Case 2 although severe atheroma was present in the abdominal aorta, it was minimal in the thoracic portion. On the other hand, Case 3 displayed the typical features of uncomplicated atheroma with thrombosis and there was no suggestion of any superadded inflammatory lesion. Atheroma was presumed to be the cause of the arterial obstruction in Case 5 also.

Congenital Anomalies. In Case 2 the innominate and right common carotid artery arose from a common root. An identical anomaly was noted by Frövig and Löken (1951) while Cohen and Davie (1933) demonstrated a common origin of the left common carotid and left subclavian arteries. Broadbent (1875) mentioned that in his case the orifices of the innominate and the left common carotid were unusually crowded together, while the left vertebral artery arose from the aortic arch close to the origin of the left subclavian, narrowing the orifice of the latter. Such anomalies may play a subsidiary part in the causation of the arterial obstruction when inflammatory or atheromatous changes are present. The true congenital malformations of the arch such as coarctation and patent ductus arteriosus are not among the causes of pulseless disease and we regard the moderate degree of coarctation in Case 2, which has not hitherto been described in this disease, as coincidental. It was presumably the cause of the poor circulation in the lower limbs. 


\section{Symptomatology and Clinical Features}

The predominating symptoms are cerebral and ocular, and their severity is dependent upon the degree of carotid obstruction. The disease may cause no disability, as in Cases 4 and 5 , when the cerebral circulation is unimpaired. Vertigo and syncopal attacks, especially in the erect posture, are common and the patient may assume a bowed position when sitting that, together with facial pallor and listless expression, tends to give a characteristic appearance. Ross and McKusick (1953) stated that pressure over the carotid sinus produced syncope in seven instances. Severe headache is frequent, and hemiplegia and aphasia due to cerebral ischæmia or infarction have often been described. The ocular manifestations have been ably summarized by Paterson (1957). Transient blurring of vision, often accompanied by faintness, may be the earliest symptom of the disease. Later, progressive diminution in visual acuity occurs. A characteristic and early ophthalmoscopic finding is "sludging" or "snail-tracking" observable in the retinal vessels due to aggregation of red blood cells as the circulation slows. Ferguson (1951) described this phenomenon in Cases 1 and 2. Light pressure upon the eyeball may halt the retinal blood-flow. Other changes include a wreath-like arterio-venous anastomosis around the papilla, and retinal exudates and hæmorrhages (Case 2) and venous or arterial thrombosis. An important complication is the rapid formation of cataract (Cases 1 and 2). It was present in 7 of the 18 cases collected by Skipper and Flint (1952) and was bilateral in two of them.

There may be ready fatiguability of the jaws or of the upper limbs (Case 3) but trophic changes in the latter do not occur. Rarely, perforation of the nasal septum, collapse of the bridge of the nose, or atrophy of the facial bones may be present. In the early case described by Savory (1856) sloughing of the left parietal region eventually exposed the cerebral hemisphere.

\section{The Cardiovascular Anomalies}

When the blood flow through both carotid arteries is grossly impaired, the cerebral circulation is maintained chiefly through the vertebral arteries which, as a rule, arise from the subclavians distal to the obstruction. If the vertebral arteries become occluded it would seem that sufficient cerebral circulation cannot be maintained to support life. Thus Harbitz (1926) found complete obstruction of the right and partial obstruction of the left vertebral at autopsy and in Case 3 the proximal portion of the left vertebral was thrombosed.

The blood pressure is either unrecordable or very low in the arms, circulation through which is maintained by anastomotic channels similar to those concerned in coarctation of the aorta. As demonstrated by Frövig and Löken (1951) and by Mengis et al. (1958) the flow in the anastomotic vessels is from below upwards. As in coarctation, anastomotic vessels may sometimes be felt pulsating over the back (Cases 1,2, and 5) and rib-notching may be demonstrated radiologically. A common clinical sign noted by several observers and by us in four of our five cases, is a systolic murmur above one or other clavicle, presumably produced in an anastomotic vessel. Except in syphilitic or atheromatous patients the heart is usually normal clinically though retrosternal discomfort may occur. In the 64-year-old woman described by Barker and Edwards (1955) death ensued from cardiac infarction though the coronary arteries were healthy except for narrowing of their ostia.

In contrast to the brachial hypotension, the blood pressure in the legs is usually raised and may reach a high level (Cases 1, 4, and 5). The cause of this is quite unknown. Rarely, the pulses may be absent in the legs (Case 3) as described by Bustamente et al. (1954) in two men, aged 51 and 52 years respectively; the obstruction was thought to be arteriosclerotic.

\section{DIAGNOSIS}

The absence of pulse in the arm makes diagnosis easy in fully-developed cases, but difficulty may arise in the early stage of the disease when the pulse may be absent in one arm only. Differentiation must then be made from aberrant radial artery, thoracic outlet compression syndrome, 
dissecting aneurysm, high coarctation of the aorta, embolism, and localized arterial thrombosis of indeterminate origin (Learmouth $e t$ al.). Apart from the more obvious diagnostic procedures such as screening of the chest and serological tests for syphilis, serial angiograms are of value in demonstrating the obstruction. Ross and McKusick (1953) recommend aortography and retrograde filling by contrast medium of the affected arteries to determine the peripheral extent of the stenosis, but these procedures are not devoid of risk.

\section{Prognosis and Treatment}

In general, the prognosis is poor, and the course is usually one of steady deterioration, progressive blindness, and death from cerebral infarction. It appears to be worse in syphilitic and arteriosclerotic cases, with their accompanying hazards, than in the non-specific arteritis type affecting principally young women in which moderate activity may continue for several years (Case 1). According to Kalmansohn and Kalmansohn (1957) the duration of life from the onset of symptoms varies from $1 \frac{1}{2}$ to 14 years and Jervell (1954) and Ask-Upmark (1954) record patients alive 14 years after the initial symptoms. It is not surprising that little is known of the therapy of this rare disease. Lampen and Wadulla (1950) and others noted improvement in the pulse in syphilitic cases with anti-syphilitic treatment, and by analogy with temporal arteritis the steroids are worthy of trial in younger patients when it is concluded that non-specific arteritis is present; Gibbons and King (1957) reported symptomatic improvement with cortisone therapy and we think this is most likely to prove successful when the E.S.R. is high and the disease is in its early stages. Anti-coagulant therapy has proved disappointing.

The various surgical measures recommended include denervation of the carotid sinus, cervical sympathectomy, thrombectomy, and reconstructive operations. As the arterial obstruction is strictly segmental and rarely extends beyond the bifurcation of the carotids and the supraclavicular portion of the subclavian arteries, it may be possible, in certain instances, to restore the continuity of the arterial circulation by nylon grafts (De Bakey et al., 1958).

\section{SUMMARY}

Pulseless disease is due to an obliterative process in the great branches of the aortic arch and five cases of this rare disease are described. Two of these proved fatal and the necropsy and histological findings are given. In one of them, the cause was considered to be non-specific arteritis; in the other atheroma. The ætiology of pulseless disease may be syphilitic arteritis, non-specific arteritis, or atheroma. Non-specific arteritis is the usual cause in young women. The possibility that congenital anomalies of the origins of the aortic arch branches may play a part is also discussed. The symptomatology, cardiovascular anomalies, diagnosis, prognosis, and treatment are described.

Our thanks are due to Professor D. H. Collins for helpful advice, to Dr. R. S. Weetch for permission to publish Case 3, and to the Editor of the British Medical Journal for allowing us to reproduce much of the clinical description of Cases 1 and 2. We are also indebted to Mr. A. S. Foster for the drawings.

\section{REFERENCES}

Ask-Upmark, E. (1954). Acta med. Scand., 149, 161.

Barker, N. W., and Edwards, J. E. (1955). Circulation, 11, 486.

Beneke, R. (1925). Virchows. Arch., 254, 722.

Broadbent, W. H. (1875). Trans. clin. Soc. Lond., 8, 165.

Bustamente, R. A., Milanes, B., Casas, R., and de la Torre, A. (1954). Angiology, 5, 479.

Caccamise, W. C., and Whitman, J. F. (1952). Amer. Heart J., 44, 629.

Cohen, H., and Davie, T. B. (1933). Lancet, 1, 852.

De Bakey, M. E., Morris, G. C., Jordan, G. L., and Cooley, D. A. (1958). J. Amer. med. Assoc., $166,998$.

Ferguson, W. J. W. (1951). Proc. Roy. Soc. Med., 44, 978.

Frövig, A. G., and Löken, A. C. (1951). Acta psychiatrica neurol., 26, 313.

Gibbons, T. B., and King, R. L. (1957). Circulation, 15, 845.

Harbitz, F. (1926). Arch. Path. Lab. Med., 1, 499.

Jervell, A. (1954). Amer. Heart. J., 47, 780.

Kalmansohn, R. B., and Kalmansohn, R. W. (1957). Circulation, 15, 237.

Lampen, H., and Wadulla, H. (1950). Dtsch. med. Wschr., 75, 144. 
Learmonth, J. R., Blackwood, W., and Richards, R. L. (1944). Edin. med. J., 51, 1. Marinesco, G., and Kreindler, A. (1936). Presse méd., 44, 833.

Mengis, C. L., Dubilier, W., and Barry, K. G. (1958). Amer. Heart J., 55, 435.

Paterson, M. W. (1957). Scot. med. J., 2, 57.

Ross, R. S., and McKusick, V. A. (1953). Arch. intern Med., 92, 701.

Savory, W. S. (1856). Med. Chir. Trans., 39, 205.

Sen Gupta, S. N., and Ghosh, J. C. (1957). Brit. med. J., 1, 137.

Shikhare, P. V. (1921). Indian J. Med., 2, 326.

Shimizu, K., and Sano, K. (1951).Jour. Neuropath. Clin. Neurol., 1, 37.

Skipper, E. W., and Flint, F. J. (1952). Brit. med. J., 2, 9.

Takayashu, M. (1908). Acta Soc. Ophthal. Jap., 12, 554. 